\title{
A study of water chemistry extends the benefits of using silica-based nanoparticles on enhanced oil recovery
}

\author{
Luky Hendraningrat • Ole Torsæter
}

Received: 6 January 2015/Accepted: 1 February 2015/Published online: 19 February 2015

(c) The Author(s) 2015. This article is published with open access at Springerlink.com

\begin{abstract}
Chemistry of the injected water has been investigated as an important parameter to improve/enhance oil recovery (IOR/EOR). Numerous extensive experiments have observed that water chemistry, such as ionic composition and salinity, can be modified for IOR/EOR purposes. However, the possible oil displacement mechanism remains debatable. Nanoparticle recently becomes more popular that have shown a great potential for IOR/EOR purposes in lab-scale, where in most experiments, waterbased fluid were used as dispersed fluid. As yet, there has been no discussion in the literature on the study of water chemistry on enhanced oil recovery using silica-based nanoparticles. A broad range of laboratory studies involving rock, nanoparticles and fluid characterization; fluidfluid and fluid-rock interactions; surface conductivity measurement; coreflood experiment; injection strategy formulation; filtration mechanism and contact angle measurement are conducted to investigate the impact of water chemistry, such as water salinity and ionic composition including hardness cations, on the performance of silicabased nanoparticles in IOR/EOR process and reveal possible displacement mechanism. The experimental results demonstrated that water salinity and ionic composition significantly impacted oil recovery using hydrophilic silica-based nanoparticles and that the oil recovery increased with the salinity. The primary findings from this
\end{abstract}

L. Hendraningrat $(\bowtie) \cdot O$. Torsæter

Department of Petroleum Engineering and Applied Geophysics,

Norwegian University of Science and Technology, NTNU,

7491 Trondheim, Norway

e-mail: lucker83@gmail.com study are that the water salinity, the ionic composition and the injection strategy are important parameters to be considered in Nano-EOR.

Keywords Enhanced oil recovery - Nanoparticles · Salinity · Ionic composition · Wettability alteration

$\begin{array}{ll}\text { Abbreviations } \\ \text { BET } & \text { Brunauer-Emmett-Teller } \\ \text { COBR } & \text { Crude oil/brine/rock } \\ \text { EDX } & \text { Energy-dispersive X-ray } \\ \text { EOR } & \text { Enhanced oil recovery } \\ \text { IFT } & \text { Interfacial tension } \\ I_{\mathrm{w}} & \text { Wettability index } \\ \text { Nano-EOR } & \text { Nanofluid as an enhanced oil recovery/ } \\ & \text { tertiary process } \\ \text { NF } & \text { Nanoflooding as a tertiary process } \\ \text { NPs } & \text { Nanoparticles } \\ \text { OOIP } & \text { Original oil in place } \\ \text { PV } & \text { Pore volume } \\ \text { ppm } & \text { Parts per million } \\ \text { ROS } & \text { Residual oil saturation } \\ \text { RRF } & \text { Residual retention factor } \\ \text { SARA } & \text { Saturates, aromates, resins and asphalthens } \\ \text { SEM } & \text { Scanning electron microscope } \\ \text { SSW } & \text { Synthetic sea water } \\ \text { SWW } & \text { Strongly water-wet } \\ S_{\text {wi }} & \text { Initial water saturation } \\ \text { TDS } & \text { Total dissolved solids } \\ \text { XRD } & \text { X-ray diffraction } \\ \text { WF } & \text { Waterflooding as a secondary flooding } \\ & \text { process } \\ \text { WC } & \text { Water cut } \\ \text { wt\% } & \text { Weight percentage } \\ & \end{array}$

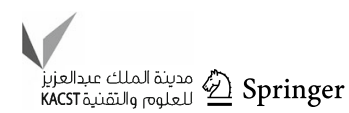




$\begin{array}{ll}\sigma_{1} & \text { Interfacial tension of the liquid phase } \\ \sigma_{\mathrm{s}} & \text { Interfacial tension of the solid phase } \\ \sigma_{\mathrm{sl}} & \begin{array}{l}\text { Interfacial tension between the liquid and the } \\ \text { solid phases }\end{array} \\ \theta & \text { Contact angle }\end{array}$

\section{Introduction}

Worden et al. (1999) defined formation water as the water that occurs naturally within the pores of sedimentary rock and is free to move under appropriate hydrodynamic conditions. During hydrocarbon production, formation water may be produced along with hydrocarbons and is measured as the water cut (WC). In typical oilfield practice, this water that is produced from a petroleum reservoir may be re-injected (after surface treatment) to maintain the pressure in the reservoir or for water flooding as a secondary recovery process (Anderson 1987). Formation water may exhibit significant variations and unique physical and chemical properties (e.g., salinity, composition, etc.) because of the various thermodynamic processes in the subsurface (Houston 2007). However, the most important processes are the depositional environment (e.g., the climate, the sedimentation state, the location and the source of sedimentation), evaporation and the dissolution of evaporates (Houston 2007). Recent studies have shown that oil production from waterflooding can be enhanced by controlling the salinity and ionic composition of the water (Jadhunandan and Morrow 1995; Yildiz et al. 1999; Webb et al. 2004; and Lager et al. 2006). Numerous laboratory experiments were subsequently performed, showing that low salinity (i.e., in the 1,000-2,000 ppm range) can improve oil recovery (Tang and Morrow 1997; Morrow et al. 1998; Tang and Morrow 1999a, b; Zhang et al. 2007; Buckley and Morrow 2010; Kumar et al. 2010; Loahardjo et al. 2010; Morrow and Buckley 2011; and Hadia et al. 2013). However, the primary oil displacement mechanism remains controversial. Skauge (2013) identified critical parameters to describe low salinity mechanisms in sandstone such as multi-component ionic exchange, fines migration, wettability alteration, electrical double layer effects, microscopically diverted flow and $\mathrm{pH}$-driven wettability alteration. Dang et al. (2013) considered that the most reliable mechanism among these proposed mechanisms is the wettability modification toward a more waterwetting state, as observed by Jadhunandan and Morrow (1995); Tang and Morrow 1999a; Drummond and Israelachvili (2002, 2004); Vledder et al. (2010); and Zekri et al. (2011). In addition, ionic exchange among the injected water, the formation water and mineral dissolution/precipitation products in low salinity water can lead to the adsorption of divalent ions and promote mineral dissolution, thereby altering the wettability. Consequently, ionic exchange affects features of the relative permeability curves such as the shape of the curve and the end points corresponding to high oil relative permeability and low water relative permeability (Webb et al. 2004; Rivet 2009; and Fjelde et al. 2012).

As yet, there has been no discussion in the literature on the effects of water salinity and ionic composition on novel enhanced oil recovery using nanofluids. Nanofluids are a new class of engineering fluids that represent a new interdisciplinary area of considerable importance where nanoscience, nanotechnology and thermal engineering converge ( $\mathrm{Yu}$ and Xie 2012). A nanofluid consists of nanoparticles (NPs) with average sizes below $100 \mathrm{~nm}$ that are suspended in a traditional heat transfer fluid such as water, oil or ethylene glycol (Das et al. 2008). A nanofluid is a two-phase systems consisting of a solid and a liquid (Yu and Xie 2012), i.e., the NPs solid phase is usually dispersed in a liquid. The water salinity is a critical factor in polymer flooding. The degree of shear degradation and retention increases with the water salinity, which in turn decreases the ability of polymer to enhance the mobility of the molecules.

Therefore, the objective of this study was to evaluate the effects of water salinity and ionic composition on oil recovery using nanofluids flooding with hard water. Synthetic sea water (SSW) of varying compositions was prepared using sodium chloride, potassium chloride and hard water at water salinities ranging from 3,000 to $100,000 \mathrm{ppm}$. The base SSW consisted of $3 \mathrm{wt} \%$ sodium chloride $(\mathrm{NaCl}$ with 30,000 ppm TDS). The Berea sandstone cores used in this study were strongly water-wet (SWW) with an Amott-Harvey wettability index $\left(I_{\mathrm{w}}\right)$ between +0.7 and +0.9 . Characterization processes were conducted on the cores, crude oil and NPs. A two-phase displacement test was carried out by injecting a silicabased nanofluid as a tertiary process (Nano-EOR) through Berea sandstone cores using various nanofluids at room conditions. Room temperature was selected as a starting point of study to figure out the fundamental behavior before going further to more complicated condition such as reservoir condition. An injection cycle scheme was developed to demonstrate the potential of using a silica-based nanofluid in a novel enhanced oil recovery (EOR) process. The oil displacement mechanism was identified by determining the crude oil/brine/rock (COBR) interactions by measuring the contact angle of a water-wet system (using quartz plates as the solid phase), particle retention and performing an effluent analysis. 


\section{Materials and experimental method}

Core preparation and characterization

In this study, several outcrop cores were used as representative reservoir rock that was cut from a huge block of Berea sandstone. Potts and Kuehne (1988) identified Berea sandstone core for use in laboratory coreflooding experiments because of uniform rock properties, commercial availability and low cost. Berea sandstone also exhibits a wide range of porosities and permeabilities. Figure 1 shows that the cores had an average diameter and length of 3.8 and $4.0 \mathrm{~cm}$, respectively. The measured helium porosity ranged from 15 to $17 \%$. The pore volume (PV) of the cores ranged between 7 and $8 \mathrm{~cm}^{3}$. The permeability to liquid (SSW) ranged from 100 to $600 \mathrm{mD}$. Selected cores were used for characterization purposes. A microscopic characterization was conducted using a scanning electron microscope (SEM). Energy-dispersive X-ray (EDX) spectrometry and X-ray diffraction (XRD) have been performed for mineralogy identification. Hendraningrat and Torsaeter (2014) used EDX and XRD to show that the selected cores were dominated by quartz (83-93\%) and minor minerals, such as alkali feldspar (max. $8 \mathrm{wt} \%$ ) and pyroxene $(<1 \mathrm{wt} \%)$ and that the pore throat size was in the micron range. Therefore, these results for the mineralogy and the pore-throat size were assumed to be representative of all of the core plugs investigated in this study. Wu and Firoozabadi (2010) conducted coreflood experiments showing that Berea sandstone is similar to sandstones obtained from reservoir cores.

\section{Nanoparticles}

Fumed hydrophilic silica $\left(\mathrm{SiO}_{2}\right) \mathrm{NPs}$ from Evonik Degussa were used in this study. The NPs had the appearance of a soft white powder and an average primary particle size of $7 \mathrm{~nm}$. The NPs were characterized using a scanning electron microscope (SEM, Zeiss Supra 55VP), as shown in Fig. 2. NPs look much bigger than their primary particle

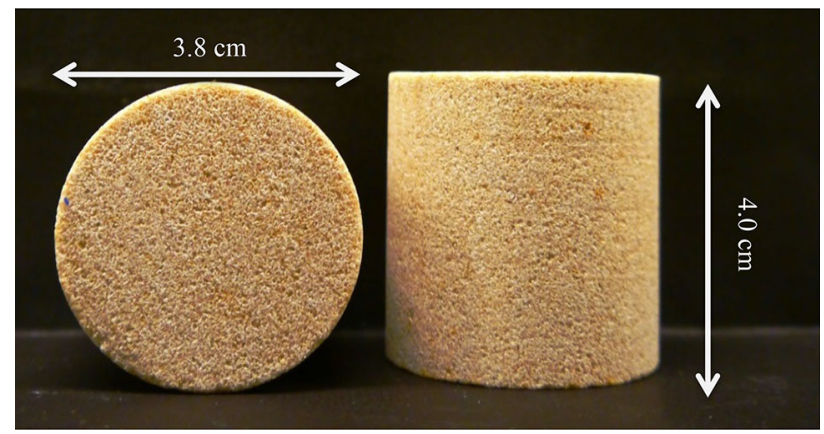

Fig. 1 A core sample with its dimensions

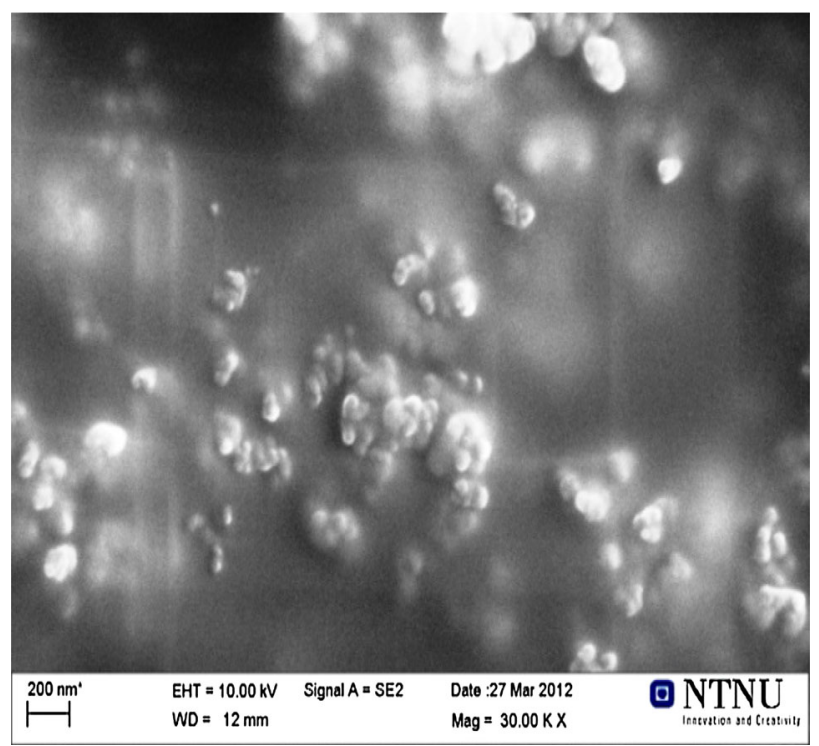

Fig. 2 Morphology and elemental analysis of $\mathrm{SiO}_{2} \mathrm{NPs}$ under SEM (magnification $30 \mathrm{k}$ times)

Table 1 Nanoparticles properties

\begin{tabular}{lll}
\hline Properties & Unit & Value \\
\hline Average primary particle size & $\mathrm{nm}$ & 7 \\
Specific surface area & $\mathrm{BET}\left(\mathrm{m}^{2} / \mathrm{g}\right)$ & $300 \pm 30$ \\
Bulk density & $\mathrm{g} / \mathrm{L}$ & 50 \\
$\mathrm{pH}(4-5 \%$ in dispersion $)$ & Unit & $3.7-4.7$ \\
$\mathrm{SiO}_{2}$ & wt $\%$ & 99.8 \\
$\mathrm{Al}_{2} \mathrm{O}_{3}$ & wt $\%$ & $\leq 0.05$ \\
$\mathrm{TiO}_{2}$ & wt $\%$ & $\leq 0.03$ \\
$\mathrm{HCl}$ & wt $\%$ & $\leq 0.025$ \\
$\mathrm{Fe}_{2} \mathrm{O}_{3}$ & wt $\%$ & $\leq 0.003$ \\
\hline
\end{tabular}

size because they were on a secondary form (aggregation). Most NPs easily aggregated because they have large surface-to-volume ratio due to the small particle size. Materials with high surface-to-volume ratios react at much faster rates because additional surfaces are available to react. The properties of the NPs are summarized in Table 1.

\section{Synthetic sea water}

Various synthetic sea water (SSW) were prepared to serve as representative reservoir formation water: the fluid properties of these SSW are shown in Table 2. Salinity is a measure of the total dissolved salts in solution; however, the term "salinity" is often used interchangeably with the term "total dissolved solids (TDS)", which is defined as the total amount of the inorganic and organic non-particulate material in a sample (Houston 2007). Using 
Table 2 Synthetic sea water properties at room condition

\begin{tabular}{|c|c|c|c|c|c|c|}
\hline SSW type & Composition & TDS, ppm & $\begin{array}{l}\text { Density } \\
\left(\mathrm{g} / \mathrm{cm}^{3}\right)\end{array}$ & $\begin{array}{l}\text { Viscosity } \\
(\mathrm{cP})\end{array}$ & $\mathrm{pH}$ & $\begin{array}{l}\text { Surface conductivity } \\
(\mathrm{mV})\end{array}$ \\
\hline A & $\mathrm{NaCl} 3.0(\mathrm{wt} \%)$ & 30,000 & 1.0220 & 1.001 & 6.76 & 14.2 \\
\hline $\mathrm{B}$ & $\mathrm{NaCl} 0.3(\mathrm{wt} \%)$ & 3,000 & 1.0004 & 1.003 & 5.94 & 44.2 \\
\hline $\mathrm{C}$ & $\mathrm{NaCl} 10$ (wt $\%)$ & 100,000 & 1.0733 & 1.059 & 6.90 & 14 \\
\hline $\mathrm{D}$ & $\mathrm{KCl} 3.0(\mathrm{wt} \%)$ & 30,000 & 1.0171 & 1.063 & 5.601 & 63 \\
\hline $\mathrm{E}$ & $\mathrm{NaCl}(2.7 \%)+\mathrm{CaCl}_{2} .2 \mathrm{H}_{2} \mathrm{O}(0.57 \mathrm{wt} \%)$ & 30,000 & 1.0215 & 1.047 & 6.029 & 38 \\
\hline $\mathrm{F}$ & $\mathrm{NaCl}(2.7 \%)+\mathrm{MgCl}_{2} \cdot 6 \mathrm{H}_{2} \mathrm{O}(1.01 \mathrm{wt} \%)$ & 30,000 & 1.0196 & 1.047 & 6.002 & 38.9 \\
\hline
\end{tabular}

representative sea water composition analyses by Houston (2007) for sedimentary basins around the world, the major salt components were considered to be $\mathrm{Na}^{+}, \mathrm{K}^{+}, \mathrm{Ca}^{2+}$, $\mathrm{Mg}^{2+}, \mathrm{Cl}^{-}, \mathrm{HCO}_{3}{ }^{-}$and $\mathrm{SO}_{4}{ }^{2-}$, with $\mathrm{pH}$ values ranging from 5.73 to 6.70 and TDS values ranging between hundreds of ppm and 300,000 ppm. In this study, a mixture of $3.0 \mathrm{wt} \%$ sodium chloride ( $\mathrm{NaCl}$; TDS approx. 30,000 ppm) and de-ionized water was used as the base SSW. Other SSW of various compositions and salinities ranging from 3,000 to $100,000 \mathrm{ppm}$ were mixed with NPs and used in a tertiary flooding process (Nano-EOR). The divalent salt ions, $\mathrm{Ca}^{2+}$ and $\mathrm{Mg}^{2+}$, were used to investigate the effect of hardness on the behavior and performance of the nanoparticles. The density and viscosity were measured using a pycnometer and a Brookfield rotating viscometer (model LVDV-II $+\mathrm{P}$ ), respectively. The $\mathrm{pH}$ and the surface conductivity were measured using a digital $\mathrm{pH}$ meter Metrohm (serial 827).

\section{Nano fluid preparation}

The NPs were synthesized using various SSW at a weight concentration of $0.05 \mathrm{wt} \%$. This concentration was selected based on our previous study to determine the optimum concentration of silica NPs (Hendraningrat et al. 2013a). The nanofluids were synthesized using various types of SSW using high-speed magnetic stirring and agitated by ultra-sonication at amplitude of 60-100\% (for an output power of 90-100 Watts). The nanofluid properties are presented in Table 3. The NPs significantly affected the nanofluid properties by lowering in the $\mathrm{pH}$ and increasing the surface conductivity.

Crude oil characterization

In this study, a degassed light crude oil from a field in the North Sea was used as the oleic phase. This crude oil was characterized by performing a saturates, aromates, resins and asphalthenes (SARA) analysis in which the numbers of acids and bases were measured. Table 4 shows the crude oil properties.
Table 3 Nanofluid properties at room condition

\begin{tabular}{lllll}
\hline Nanofluid & Density $\left(\mathrm{g} / \mathrm{cm}^{3}\right)$ & Viscosity $(\mathrm{cP})$ & $\mathrm{pH}$ & $\begin{array}{l}\text { Surface } \\
\text { conductivity }(\mathrm{mV})\end{array}$ \\
\hline $\mathrm{A}$ & 1.0150 & 1.0100 & 6.16 & 50.6 \\
$\mathrm{~B}$ & 1.0040 & 0.9567 & 5.24 & 82.1 \\
$\mathrm{C}$ & 1.0653 & 1.1067 & 5.57 & 57.2 \\
$\mathrm{D}$ & 1.0167 & 0.8970 & 4.87 & 103.5 \\
$\mathrm{E}$ & 1.0163 & 1.0333 & 5.39 & 69.9 \\
$\mathrm{~F}$ & 1.0128 & 0.9867 & 5.66 & 56.5 \\
\hline
\end{tabular}

Table 4 Crude oil properties

\begin{tabular}{llll}
\hline Properties & Unit & Value & Temperature $\left({ }^{\circ} \mathrm{C}\right)$ \\
\hline Saturates & $\mathrm{wt} \%$ & 75.12 & 22 \\
Aromates & $\mathrm{wt} \%$ & 22.59 & 22 \\
Resins & $\mathrm{wt} \%$ & 1.88 & 22 \\
Asphalthens & $\mathrm{wt} \%$ & 0.41 & 22 \\
Acid \# & $\mathrm{mg} \mathrm{KOH} / \mathrm{g}$ oil & $<0.1$ & 22 \\
Base \# & $\mathrm{mg} \mathrm{KOH} / \mathrm{g}$ oil & $0.35-0.46$ & 22 \\
Density & $\mathrm{g} / \mathrm{cm}^{3}$ & 0.83774 & 15.5 \\
Density & $\mathrm{g} / \mathrm{cm}^{3}$ & 0.8260 & 22 \\
Viscosity & $\mathrm{cP}$ & 5.1 & 22 \\
\hline
\end{tabular}

Quartz plate preparation

In this study, a series of rectangular transparent quartz plates were used as solid substrates to determine the wettability behavior of the silica-based nanofluid. The quartz plate was selected based on a core mineralogy and elemental analysis using XRD and EDX (the plate was predominantly quartz at a composition of 83-93\%). On average, each quartz plate was $2.8 \mathrm{~cm}$ long, $1.5 \mathrm{~cm}$ wide and $0.19 \mathrm{~cm}$ high. Hendraningrat et al. (2013b) first classified the wettability of a quartz plate as being strongly water-wet (SWW).

Measurement of charge stabilization of nanofluids

The stability of the nanofluids was determined by measuring the surface conductivity using digital Metrohm 
(serial 827), which is an important parameter in evaluating fluid stability. In this study, surface conductivity was used to measure the particle charge, which arises from the ionization of surface groups that are affected by the solution pH ISO 14887:2000(E) (2000). This instrument is completed for water analysis and will show the fluid properties such as $\mathrm{pH}$, surface conductivity and temperature at the same time. The surface conductivity is closely related to the surface charge (Rao 2010). Colloids with a sufficiently high surface charge will remain as discrete particles, resulting in a suspension with good stability. Decreasing the surface charge of the colloids has the opposite effect.

\section{Contact angle measurement}

The contact angle of the COBR system was measured directly on transparent quartz plates using a Goniometry KSV CAM instrument at room conditions for $3 \mathrm{~h}$. The system consisted of a quartz plate for the solid substrate, a crude oil for the oleic-phase and a nanofluid for the aqueous phase. The duration of the measurement was selected based on the typical injection time for each sequence. The measured drop shape was fitted by the YoungLaplace formula as follows:

$\sigma_{\mathrm{s}}=\sigma_{\mathrm{sl}}+\sigma_{1} \cos \theta$,

where $\sigma$ denotes the interfacial tension of the components of the system, and the indices s and 1 denote the solid and liquid phases, respectively, $\sigma_{\mathrm{s} 1}$ denotes the interfacial tension between the two phases and $\theta$ is the contact angle, which corresponds to the angle between the vectors $\sigma_{1}$ and $\sigma_{\mathrm{sl}}$.

Treiber et al. (1971) developed the following classification for the contact angle in a 3-phase system (water, oil and a rock surface): water-wet corresponds to the $0^{\circ}$ to $75^{\circ}$ range, intermediate/neutral-wet corresponds to the $75^{\circ}-$ $105^{\circ}$ range and oil-wet corresponds to the $105^{\circ}-180^{\circ}$ range. A zero contact angle shows that the denser fluid completely wets the solid.

\section{Coreflood procedure}

All of the cores were fully saturated with the SSW in a vacuum container for several days to allow equilibration with rock constituents at room temperature and a low pressure of 100 mbar (Yildiz et al. 1999). The drainage process was initiated by injection of a crude oil at an elevated rate between 1 and $40 \mathrm{~cm}^{3} / \mathrm{min}$ for $8-10 \mathrm{PV}$ until SSW production stopped, thereby establishing the initial water saturation $\left(S_{\mathrm{wi}}\right)$. The two-phase oil-water system coreflooding instrument was configured as shown in Fig. 3. The sleeve pressure and injection rate were set to constant values of $20 \mathrm{bar}$ and $0.2 \mathrm{~cm}^{3} / \mathrm{min}$, respectively, during the displacement processes. The injection rate was selected to approximate typical reservoir velocities. The displacement tests were performed using sequential flooding. In the first cycle of the forced imbibition process, the base SSW (3 wt\% $\mathrm{NaCl}$ ), which is denoted by WF1, in the 5-10 PV range was injected into the core plugs until oil production stopped or a $100 \%$ water cut (WC) was reached. Thus, residual oil saturation (ROS) occurred because of waterflooding (WF1). In the next cycle, the silica-based nanofluid in the range of 5-7 PV was injected as a tertiary recovery process (which is denoted as NF). In the postnanoflooding cycle, the (secondary) base SSW (which is denoted as WF2) in the 5-7 PV range was then re-injected into selected cores. The expelled oil from a core was recorded and measured in a two-phase glass separator during the displacement processes. The effluent water was collected in a water accumulator. A camera was installed to record the oil recovery during the displacement processes. A differential pressure transmitter in the 0-30 bar range was connected to the inlet and outlet ends of the core cell to measure and record the pressure drop across the core during the flooding processes. The effluents were collected in the water accumulator. For each sequential flooding process, the effluent was taken at the final PV value, and the $\mathrm{pH}$ and the surface conductivity alteration of the effluent were measured. The procedure was performed in this way to avoid contamination from the previous sequence.

\section{Results and discussion}

Evaluation of charge stabilization of nanofluids

Rao (2010) reported that the particle surface charge can be controlled by modifying the suspension liquid, i.e., changing the $\mathrm{pH}$, shifting the ionic environment or adding a stabilizer. In this study, the effect of ionic exchange and the salinity of the dispersed fluid were evaluated for silicabased NPs because the stability of the nanofluid has been observed to be a significant issue in enhanced oil recovery (Yu and Xie 2012; Hendraningrat et al. 2013c). Table 4 shows that different nanofluid salinities and ionic compositions corresponded to different surface conductivities. The surface conductivity decreased as the salinity was decreased from 100,000 to 3,000 ppm. The ionic composition also affected the surface conductivity. The potassium ion $\left(\mathrm{K}^{+}\right)$has a much higher surface conductivity than the sodium ion $\left(\mathrm{Na}^{+}\right)$, because potassium has a larger atomic radius and, therefore, a higher reactivity than sodium. Therefore, the single valence electron of the alkali metals is located farther away from nucleus (Wikianswers 2014). Calcium has a larger atomic radius than magnesium, which makes calcium more reactive than magnesium. However, among the ions considered in this study, potassium is the 


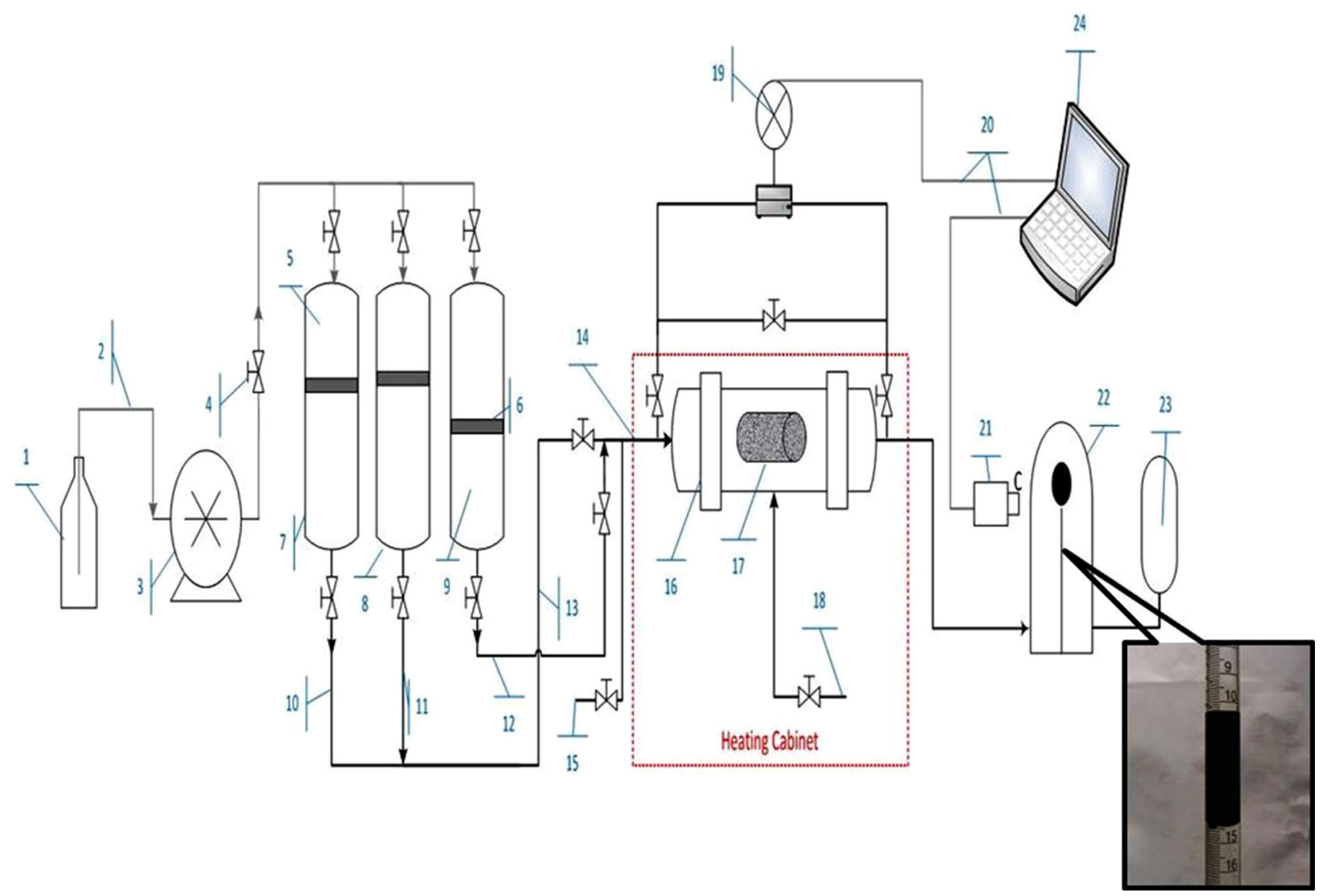

Fig. 3 Experimental setup schematic 1 pump fluid (Exxol D60), 2 injection pipe (ID $1.5 \mathrm{~mm}$ ) 3 Pump, 4 valve, 5 pump fluid in vessel-A, 6 piston plate, 7 SSW in vessel-A, 8 nanofluid in vessel-B, 9 crude oil in vessel-C, $10 \mathrm{SSW}$ pipeline, 11 nanofluid pipeline, 12 oil pipe, 13 water-phase pipeline, 14 inlet pipeline, 15 bypass valve, 16 Hassler

most reactive and exhibits the highest surface conductivity. Hendraningrat and Torsaeter (2014) observed that the higher the surface conductivity of a nanofluid, the higher its stability. The surface conductivity is inversely related to the $\mathrm{pH}$. This result can be explained in terms of the balance between two opposing forces, i.e., attractive and repulsive potentials. The balance between the van der Waals (VDW) attraction and the electrostatic repulsion can be used to explain why certain colloidal systems agglomerate whereas other systems remain as dispersed particles. The VDW attraction results from the forces between the individual molecules in each colloid. Electrostatic repulsion becomes significant when two colloids approach each other because of charge interactions, and their double layers begin to interfere. Energy is required to minimize this repulsion by creating an aggregate form. Increasing the particle surface charge particles increases the repulsive forces between particles, thereby increasing the stability of the suspension, because discrete particles are maintained and prevented from aggregating into larger particles via the process core cell inside oven, 17 core plug inside cell, 18 sleeve pressure 19 pressure transmitter, 20 Connection cable to $\mathrm{PC}, 21$ camera recorder, 22 oil-water separator, 23 water accumulator, 24 computer/PC as controller and data acquisition

known as agglomeration, which has been observed to impair rock properties (Hendraningrat et al. 2013c).

Displacement tests and mechanism

The coreflood results for the water-wet Berea cores are summarized in Table 5. In the first waterflooding sequence (WF1), sodium chloride $(30,000 \mathrm{ppm})$ was injected until $100 \%$ water cut (WC) was achieved through the Berea sandstone in all of the cases studied. This composition was similar to the initial water saturation $\left(S_{\mathrm{wi}}\right)$ composition. Our measurements showed that the $S_{\text {wi }}$ ranged from 24 to $39 \%$ PV. Craig (1971) reported that the characteristics of strongly water-wet (SWW) cores are typically greater than 20-25\% PV because water fills the small pores and forms a thin water film over the rock surfaces in a water-wet system. Consequently, the $S_{\text {wi }}$ for water-wet systems is relatively high. Several representative sister cores were taken from a previous study (Hendraningrat et al. 2013d) and a solution of $\mathrm{NaCl}$ $3.0 \mathrm{wt} \%$ with NPs $0.05 \mathrm{wt} \%$ is used as a base case. 
Table 5 Summary of displacement experiment

\begin{tabular}{|c|c|c|c|c|c|c|c|c|c|}
\hline \multirow[t]{2}{*}{ Core \# } & \multirow{2}{*}{$\begin{array}{l}\text { Initial water } \\
\text { saturation }(\% \mathrm{PV})\end{array}$} & \multicolumn{3}{|c|}{ Oil recovery (\% OOIP) } & \multicolumn{3}{|c|}{ Residual oil saturation (\% PV) } & \multirow{2}{*}{$\begin{array}{l}\text { Total recovery, } \\
(\% \text { OOIP })\end{array}$} & \multirow{2}{*}{$\begin{array}{l}\text { Injected } \\
\text { nanofluid }\end{array}$} \\
\hline & & WF1 & NF & WF2 & WF1 & $\mathrm{NF}$ & WF2 & & \\
\hline $\mathrm{H}-2$ & 24.2 & 61.70 & 5.32 & - & 29.00 & 24.90 & 24.90 & 67.02 & A \\
\hline S-1 & 36.55 & 54.65 & 0.00 & 1.98 & 28.77 & 28.77 & 27.51 & 56.63 & B \\
\hline S-2 & 32.54 & 67.24 & 15.52 & 0.86 & 22.10 & 11.63 & 11.05 & 83.62 & $\mathrm{C}$ \\
\hline S-3 & 31.25 & 54.17 & 3.13 & - & 31.51 & 29.36 & 29.36 & 57.29 & $\mathrm{D}$ \\
\hline S-4 & 27.12 & 54.31 & 3.45 & 2.59 & 33.30 & 30.79 & 28.90 & 60.34 & $\mathrm{E}$ \\
\hline S-5 & 39.86 & 53.70 & 13.89 & 4.63 & 27.84 & 19.49 & 16.71 & 72.22 & F \\
\hline
\end{tabular}

Oil Recovery Performance, Differential Pressure vs. Injected PV of Core H-2 (Nanofluid-A)

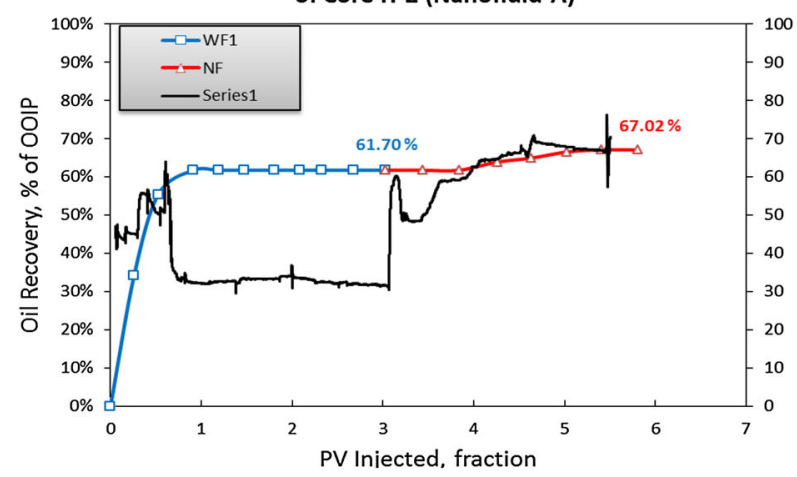

Oil Recovery Performance, Differential Pressure vs. Injected PV of Core S-2 (Nanofluid-C)

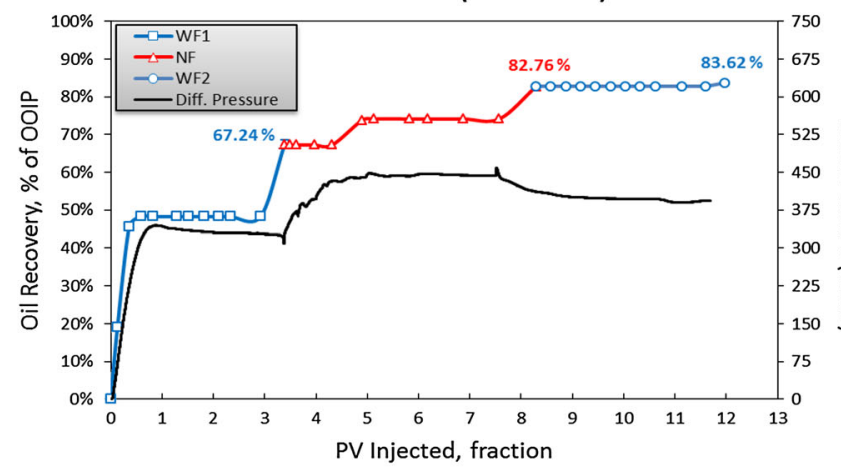

Oil Recovery Performance, Differential Pressure vs. Injected PV of Core S-4 (Nanofluid-E)

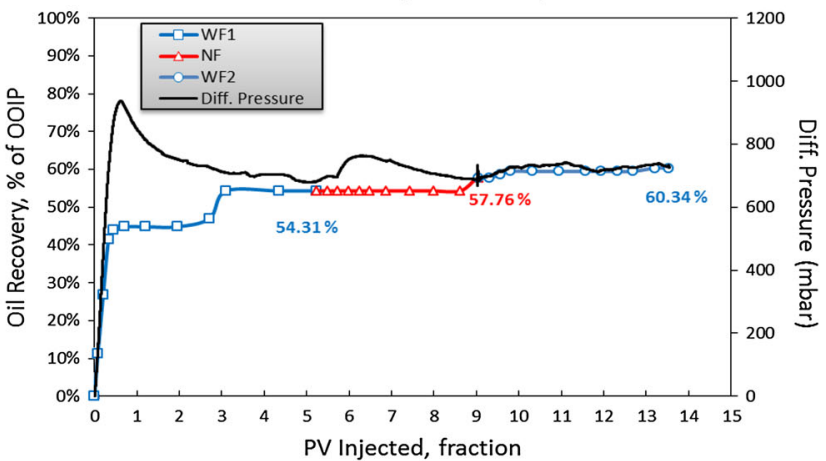

Oil Recovery Performance, Differential Pressure vs. Injected PV of Core S-1 (Nanofluid-B)

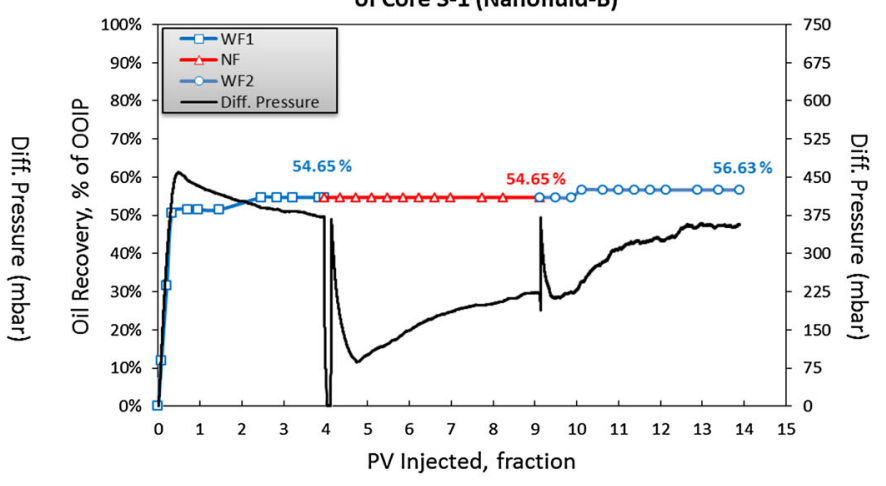

Oil Recovery Performance, Differential Pressure vs. Injected PV of Core S-3 (Nanofluid-D)

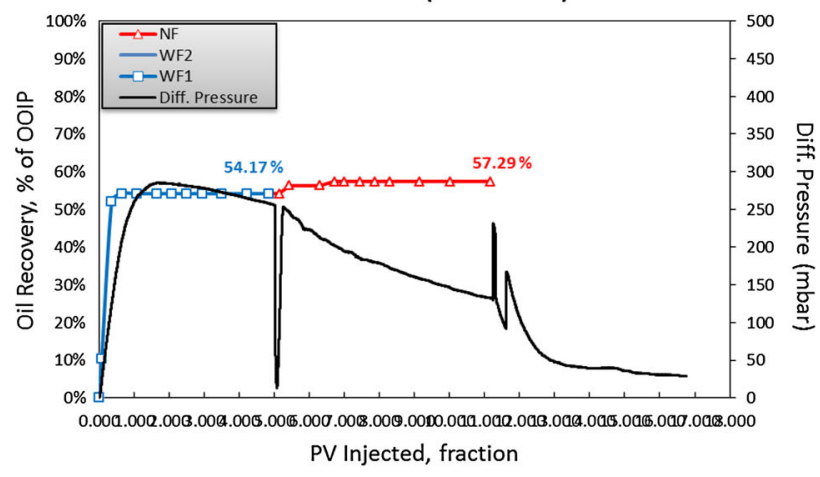

Oil Recovery Performance, Differential Pressure vs. Injected PV of Core S-5 (Nanofluid-F)

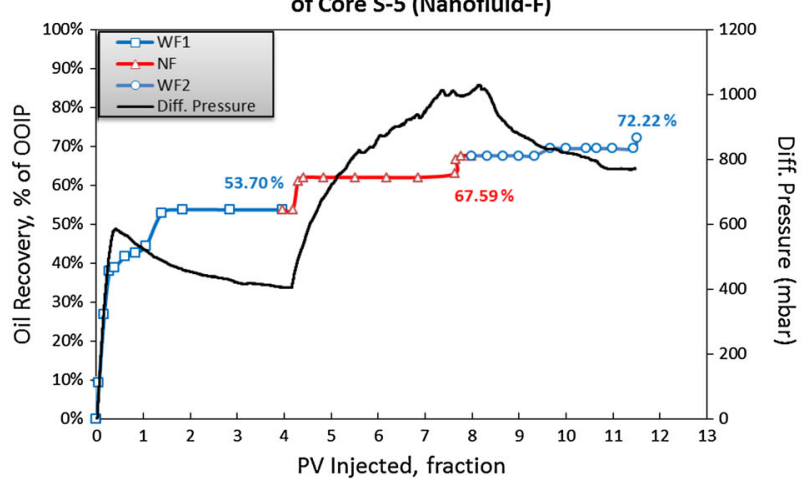

Fig. 4 Oil recovery profile, differential pressure vs. injected PV of water-wet cores 
Figure 4 shows the oil recovery performances for each sequence (WF1, NF and WF2) and the corresponding pressure drop profiles. The oil recoveries after WF1 ranged from 53 to $67 \%$ OOIP, and the ROS ranged from 22 to $34 \% \mathrm{PV}$. Oil recovery variations typically result from complex COBR interactions, such as the complexity of the pore structure and the distribution of the fluid in the pore spaces (Morrow 1990).

Injecting a nanofluid with a low salinity of approx. 3,000 ppm (Core S-1) did not affect the oil recovery. The incremental oil recovery usually increases when the water salinity is increased from 30,000 to $100,000 \mathrm{ppm}$. The results showed that nanofluid flooding is more likely using higher salinities (Core S-3). This result is significant because an incremental oil recovery of $15 \%$ points of OOIP was obtained using nanofluid-C (Core S-3). This preliminary study shows that nanofluid flooding is sensitive to the water salinity (i.e., the sodium chloride composition) and that increasing the water salinity results in a much higher incremental oil recovery that agrees with wettability alteration toward a more water-wet system, as shown in Fig. 5. Figure 6 shows the changes of the shape of a crude oil droplet on a quartz plate for nanofluids with different salinities over $3 \mathrm{~h}$. Thus, different water salinities interacted differently with the quartz surface and altered the surface property toward a more water-wet system.

The magnitude of the changes in the oil recovery in the presence of monovalent cations $\left(\mathrm{Na}^{+}\right.$and $\left.\mathrm{K}^{+}\right)$showed a similar potential for nanofluid flooding, and both cations modified the rock wettability in agreement with the incremental oil recovery results, as shown in Fig. 7. The presence of the divalent cations $\left(\mathrm{Ca}^{2+}\right.$ and $\left.\mathrm{Mg}^{2+}\right)$ in the surrounding nanofluid had a considerable effect on the rock wettability alteration and the incremental oil recovery, as shown in Fig. 8. The recoveries obtained for different ionic compositions were very close and remained in the middle range of the base case using sodium chloride at a similar salinity. Unexpected results were obtained using a nanofluid containing $\mathrm{Mg}^{2+}$ cations (Core S-5), which produced the highest incremental oil recovery of almost $14 \%$ points of OOIP for all of the cases studied. Although both types $\mathrm{E}$ and $\mathrm{F}$ of the SSWs had similar salinities of $30,000 \mathrm{ppm}$, the weight concentration of the $\mathrm{Mg}^{2+}$ cation was almost double that of the $\mathrm{Ca}^{2+}$ cation. The contact angle measurements showed that these divalent cations produced the greatest increase in the water-wetness of the system. These observations were
Fig. 5 Contact angle measurement to evaluate the effect of salinity
Fig. 6 Contact angle images of various nanofluids with different salinity after $3 \mathrm{~h}$ at room condition
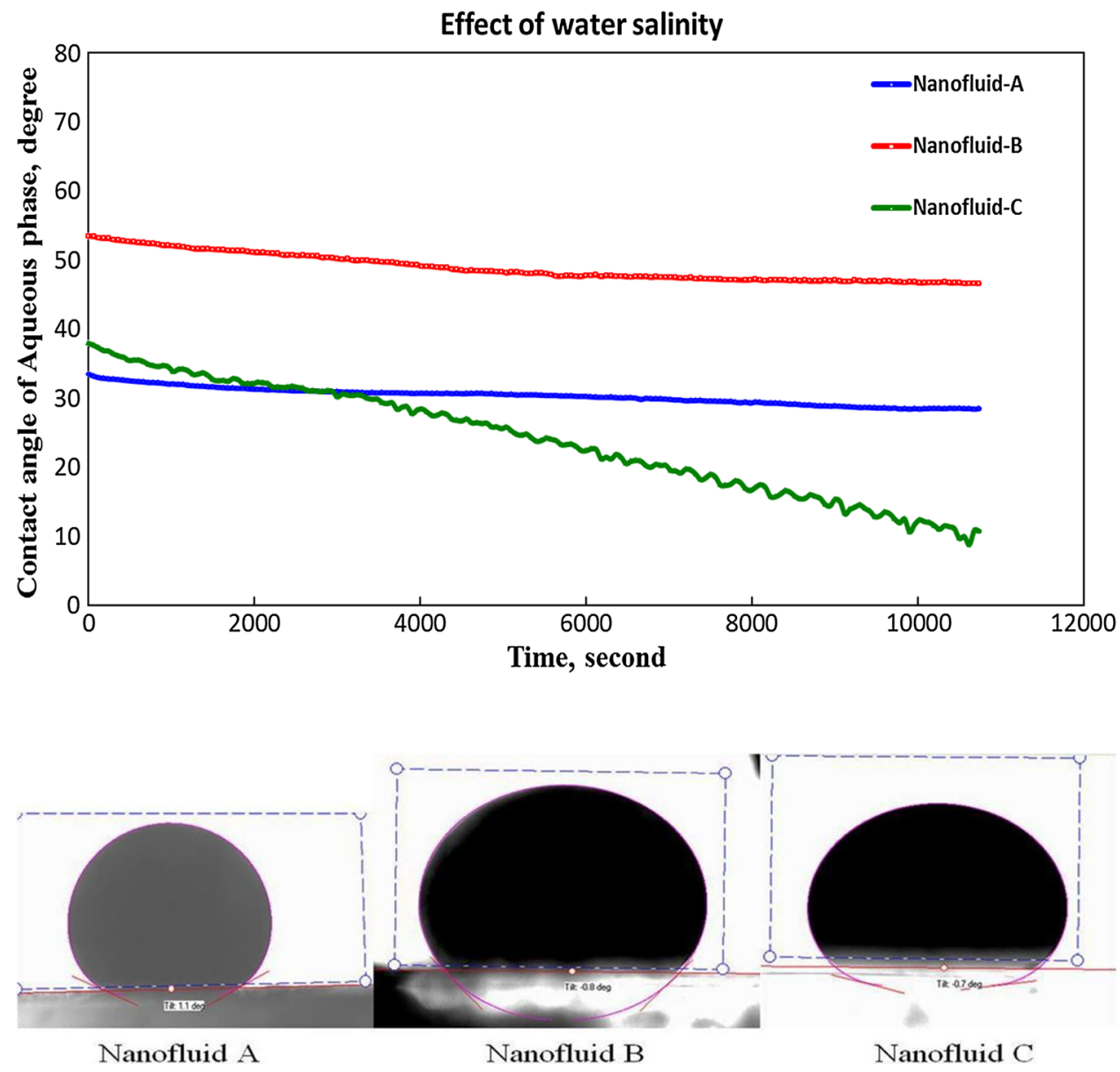
Fig. 7 Contact angle measurement to evaluate the effect of monovalent (a) and divalent (b) ionic compositions
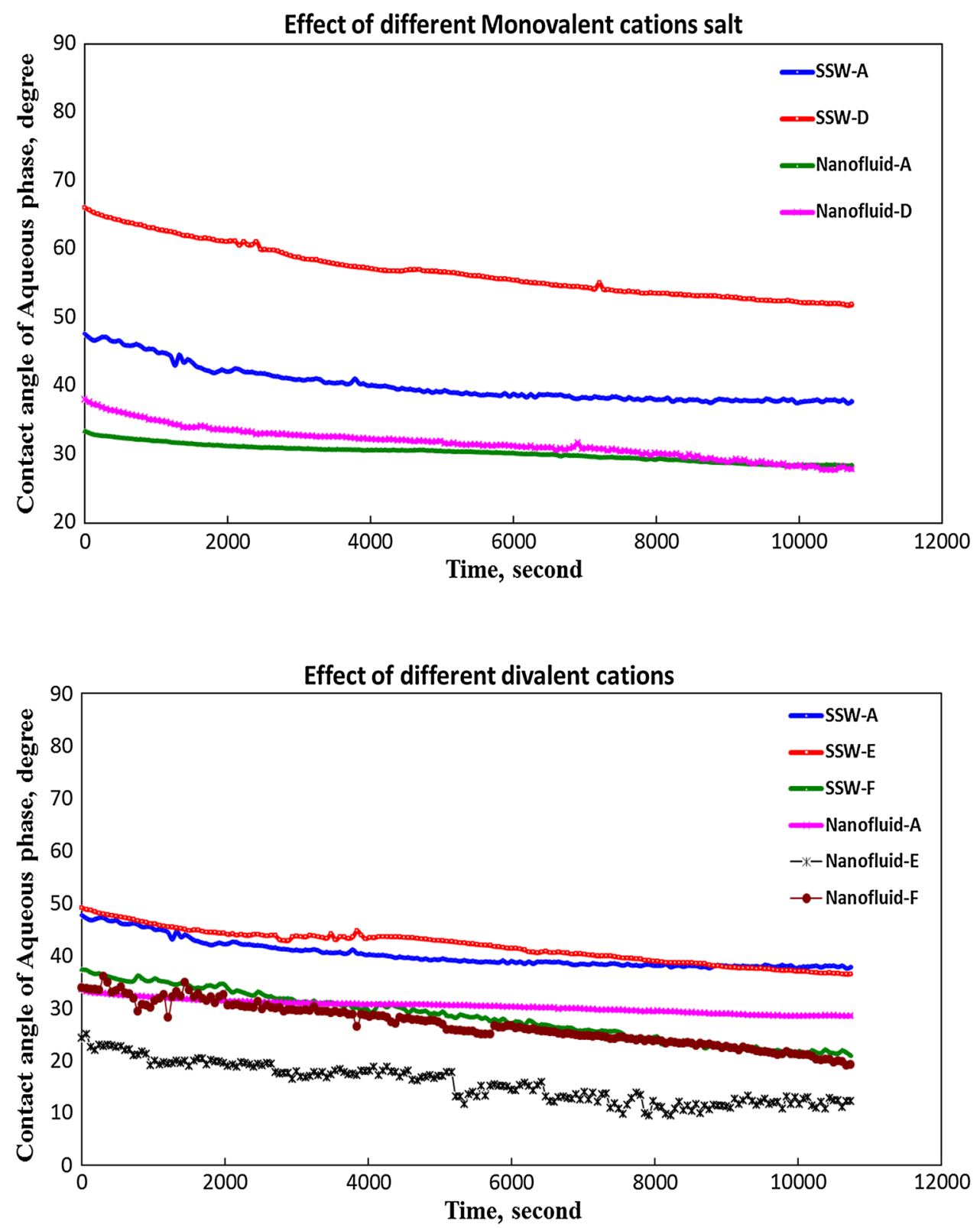

Fig. 8 Contact angle measurement to evaluate the effect of monovalent (a) and divalent (b) ionic compositions result was observed when sodium chloride was re-injected after the NF sequence achieved a $100 \%$ WC. In most cases, additional oil was recovered during the WF2 Sequence. The highest oil recovery of almost $5 \%$ points of OOIP was obtained using the nanofluid containing $\mathrm{Mg}^{2+}$. Even in the low salinity case (Core S-1 with nanofluid-B), the oil recovery was almost $2 \%$ points of OOIP. The nanofluid containing $\mathrm{K}^{+}$cations did not perform well because of a pump malfunction in the WF2 sequence. Therefore, the injection strategy associated with the incremental oil recovery could also depend on the composition and the water salinity. However, further investigation is needed to validate these results.

Figure 10 shows the filtration mechanism of NPs in Berea sandstone from observations of the inlet point of surface charge, altered the rock wettability and eventually mobilized the residual oil in the cores. Another interesting 


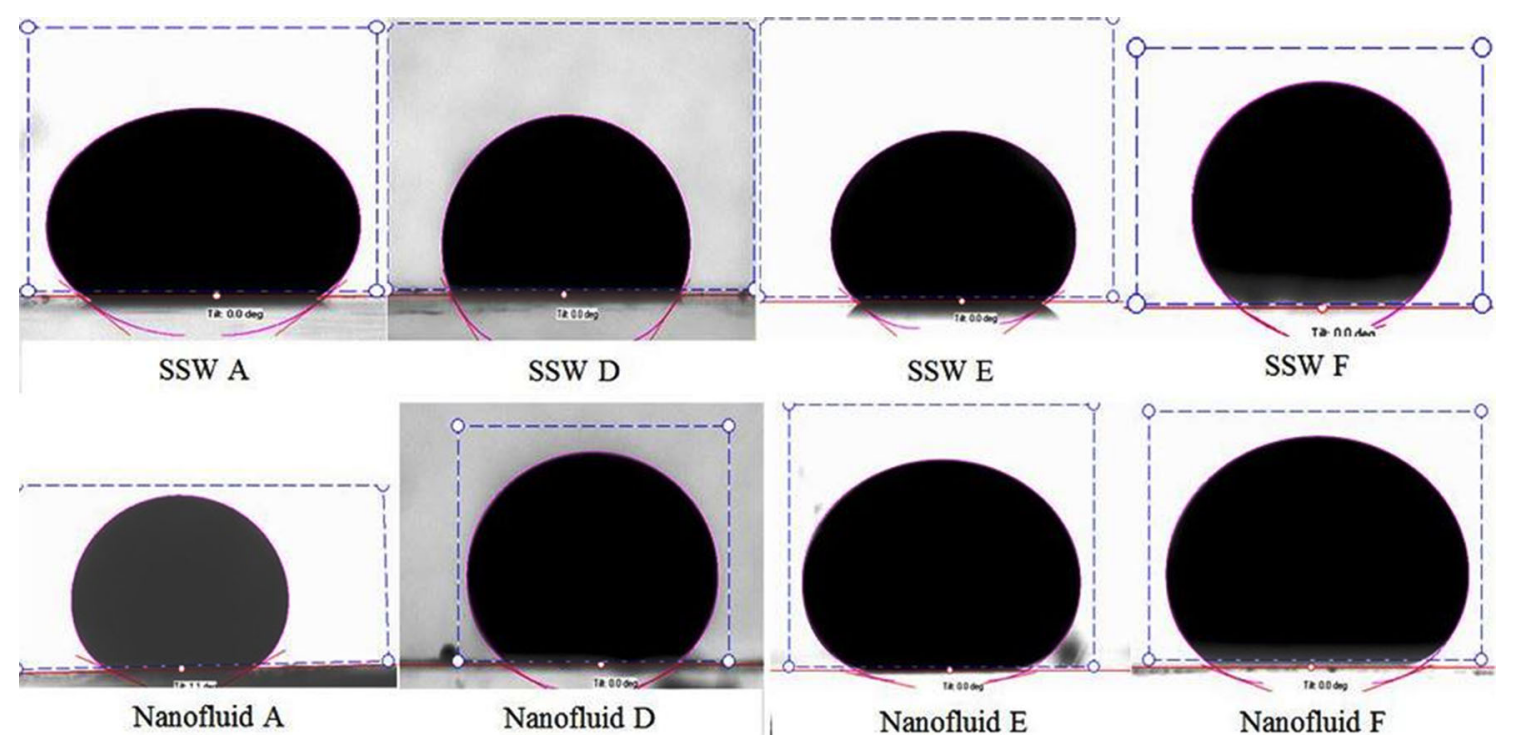

Fig. 9 Contact angle images of various synthetic sea water and nanofluid with different ionic compositions after $3 \mathrm{~h}$ at room condition

Fig. 10 Surface nano-cake observations at inlet point after injections of different nanofluids
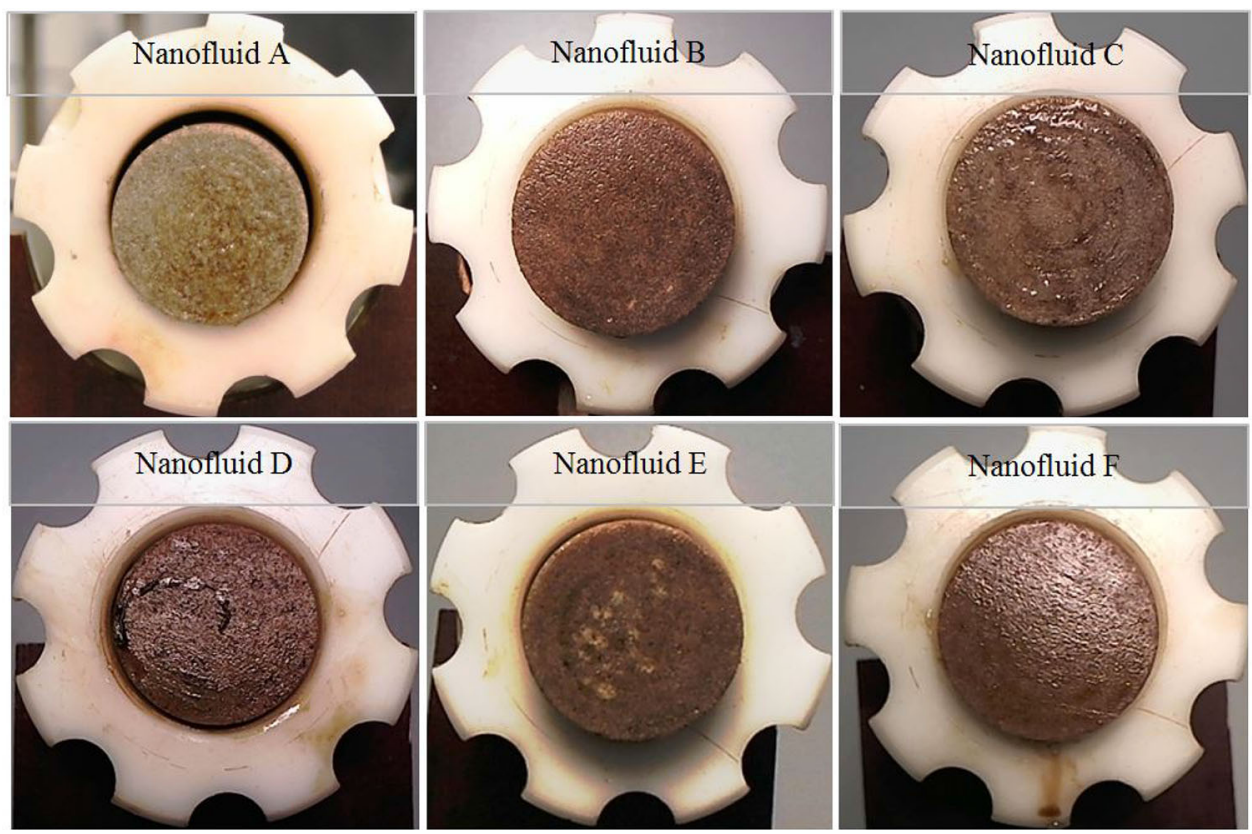

cores after the displacement tests. The formation of surface nano-cakes could not be clearly observed for all of the tested cores. Therefore, another evaluation was conducted by calculating the residual retention factor (RRF), as described by Skauge et al. (2010). The RRF is defined as the ratio between the differential pressure after and before NF. The RRF was calculated using the following formula:

$\mathrm{RRF}=\frac{\Delta P_{\text {after NF }}}{\Delta P_{\text {before } \mathrm{NF}}}$

Tables 5 and 6 show that higher RRF values corresponded to higher incremental oil recoveries after the NF and WF2 sequences. Increasing the RRF value increases the tendency of a particle to be adsorbed by the rock grain surface, resulting in aggregation. This aggregation was observed by increasing the pressure drop during the NF and WF1 sequences. This result also indicated that the NPs altered the surface rock wettability toward more water-wetness during adsorption and mobilized the residual oil in the cores. Zhang et al. (2013) reported that NP adsorption during transport in a porous medium involves physicochemical interactions between the NPs and the grain surfaces. This observation supports the results of wettability modifications from contact angle measurements. 
Table 6 Residual retention factor calculation

\begin{tabular}{lll}
\hline Core \# & Average RRF & Injected nanofluid \\
\hline H-2 & n.a & A \\
S-1 & 0.96 & B \\
S-2 & 1.19 & C \\
S-3 & n.a & D \\
S-4 & 1.05 & E \\
S-5 & 1.90 & F \\
\hline
\end{tabular}

Table 7 The $\mathrm{pH}$ and surface conductivity alteration

\begin{tabular}{llllllll}
\hline Core \# & $\mathrm{pH}$ & & & & \multicolumn{3}{c}{ Surface conductivity $(\mathrm{mV})$} \\
& WF1 & NF & WF2 & & WF1 & NF & WF2 \\
\hline H-2 & n.a & n.a & n.a & & n.a & n.a & n.a \\
S-1 & 4.450 & 4.276 & 5.619 & & 124.5 & 133.6 & 85.9 \\
S-2 & 4.452 & 4.391 & 4.607 & & 124.1 & 126.7 & 115.5 \\
S-3 & 5.934 & 5.890 & n.a & & 45.3 & 47.4 & n.a \\
S-4 & 5.736 & 5.616 & 5.401 & 49.9 & 56.1 & 67.1 \\
S-5 & 5.193 & 5.075 & 5.784 & 86 & 92.5 & 53.5 \\
\hline
\end{tabular}

The measured $\mathrm{pH}$ and surface conductivity of the effluent are summarized in Table 7. The $\mathrm{pH}$ and the surface conductivity of the injected SSW changed for all of the cores before and after the NF injection. These changes may have occurred because of the physicochemical adsorption of NPs during transport through the porous medium, resulting in wettability alteration, as previously observed from the contact angle and RRF measurements. Austad (2013) reported that active divalent ions, such as $\mathrm{Ca}^{2+}, \mathrm{Mg}^{2+}$ and $\mathrm{SO}_{4}{ }^{2-}$, can decrease the charge density. These divalent ions can contact the grain surface and alter the wettability.

However, the presence of clay in sandstone was necessary in Austad's study, unlike the Berea sandstones used in this study. The effluent observations showed that the surface conductivity decreased before and after NF process, except when the nanofluid containing $\mathrm{Ca}^{2+}$ cations was used. Thus, it is not obvious as to how to determine the relationship between the wettability alteration and the change in the $\mathrm{pH} /$ surface conductivity in the Berea sandstone rock in this study. Further investigation is needed to evaluate this issue.

\section{Concluding remarks and further works}

Different nanofluid salinities and ionic compositions affected the surface conductivity of the nanofluids. The surface conductivity decreased as the salinity decreased, which was associated with a decrease in the nanofluid stability. In addition, different ionic compositions had different effects on the surface conductivity. Nanofluid flooding is sensitive to the water salinity (i.e., the sodium chloride content). Increasing the water resulted in a much higher incremental oil recovery which agreed with the wettability alteration toward a more water-wet system. The presence of monovalent cations $\left(\mathrm{Na}^{+}\right.$and $\left.\mathrm{K}^{+}\right)$in the surrounding nanofluid exhibited similar potentials for nanofluid flooding and affected the rock wettability alteration: the cation concentrations were proportional to the incremental oil recovery. The presence of divalent cations $\left(\mathrm{Ca}^{2+}\right.$ and $\left.\mathrm{Mg}^{2+}\right)$ in the surrounding nanofluid considerably affected the rock wettability alteration and the incremental oil recovery. Additional oil was recovered when $30,000 \mathrm{ppm}$ of sodium chloride was re-injected after the NF sequence achieved a $100 \%$ WC. This injection strategy affected the incremental oil recovery and may also have depended on the composition and the water salinity of the nanofluid. The results showed that varying the water salinity and ionic composition of the nanofluid significantly affected the wettability alteration toward a more waterwetting state. These wettability modifications were in agreement with the incremental oil recovery results in most of the case studies. The incremental oil recovery increased with the RRF value. Further studies, such as a thermal stability analysis of various water salinities and ionic compositions at higher temperatures, should be conducted to have better understanding of phase behavior at reservoir temperatures, including at higher degrees of water salinity and more complex salt compositions and/or real formation water.

Acknowledgments The authors gratefully acknowledge Evonik Industries AG for providing the nanoparticles for this study and the Department of Petroleum Engineering and Applied Geophysics (NTNU) for the financial support required to complete this study and permission to publish this article.

Open Access This article is distributed under the terms of the Creative Commons Attribution License which permits any use, distribution, and reproduction in any medium, provided the original author(s) and the source are credited.

\section{SI metric conversion factors}

$$
\begin{aligned}
& \mathrm{mD} \times 9.869233 \mathrm{E}-04=\mu \mathrm{m}^{2} \\
& \mathrm{cP} \times 1.000000 \mathrm{E}+00=\mathrm{mPa} . \mathrm{s} \\
& \mathrm{dyn} / \mathrm{cm} \times 1.000000 \mathrm{E}+00=\mathrm{mN} / \mathrm{m} \\
& \text { bar } \times 1.000000 \mathrm{E}-02=\mathrm{kPa}
\end{aligned}
$$

\section{References}

Anderson WG (1987) Wettability literature survey-Part 5: the effects of wettability on relative permeability. J Pet Tech 39 (11):1453-1468. SPE-16323-PA. doi:10.2118/16323-PA

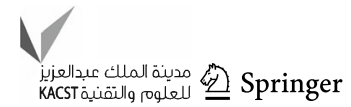


Austad T (2013) Smart water as EOR fluid in carbonates and sandstones: challengers and possibilities. Society of petroleum engineers. Extended abstracts of SPE workshop in artic, Harstad

Buckley JS, Morrow NR (2010) Improved oil recovery by low salinity waterflooding: a mechanistic review. Paper presented at 11th international symposium on evaluation of wettability and its effect on oil recovery, Calgary

Chamkalani A (2012) Correlations between SARA fractions, density, and RI to investigate the stability of asphaltene. ISRN Anal Chem (6)

Craig FF Jr (1971) The reservoir engineering aspects of waterflooding, vol 1. Monograph Series, Society of Petroleum Engineers, New York

Dang CTQ, Nghiem LX, Chen ZJ, Nguyen QP (2013) Modeling low salinity waterflooding: ion exchange, geochemistry and wettability alteration. Society of petroleum engineers. SPE-166447MS. doi:10.2118/166447-MS

Das SK, Choi SUS, Yu W, Pradeep T (2008) Nanofluids science and technology. Wiley, Hoboken. ISBN 0470074736

Drummond C, Israelachvili J (2002) Surface forces and wettability. J Pet Sci Eng 33(1-3):123-133. doi:10.1016/S0920-4105(01) 00180-2

Drummond C, Israelachvili J (2004) Fundamental studies of crude oil-surface water interactions and its relationship to reservoir wettability. J Petrol Sci Eng 45(1-2):61-81. doi:10.1016/j.petrol. 2004.04.007

Fjelde I, Asen SM, Omekeh AV (2012) Low salinity water flooding experiments and interpretation by simulations. Society of petroleum engineers. SPE-154142-MS. doi:10.2118/154142-MS

Hadia NJ, Ashraf A, Tweheyo MT, Torsæter O (2013) Laboratory investigation on effects of initial wettabilities on performance of low salinity waterflooding. J Petrol Sci Eng 105:18-25. doi:10. 1016/j.petrol.2013.03.014

Hendraningrat L, Torsaeter O (2014) Unlocking the potential of metal oxides nanoparticles to enhance the oil recovery. Offshore technology conference. OTC-24696-MS. doi:10.2118/24696-MS

Hendraningrat L, Li S, Torsaeter O (2013a) Enhancing oil recovery of low-permeability berea sandstone through optimised nanofluids concentration. Society of petroleum engineers. Paper SPE 165283-MS. doi:10.2118/165283-MS

Hendraningrat L, Li S, Torsæter O (2013b) A coreflood investigation of nanofluid enhanced oil recovery. J Petrol Sci Eng 111:128-138

Hendraningrat L, Engeset B, Suwarno S, Li S, Torsæter O (2013c) Laboratory investigation of porosity and permeability impairment in Berea sandstones due to hydrophilic nanoparticle retention. Paper SCA2013-062 presented at the international symposium of the society of core analysts held in Napa Valley, California, USA

Hendraningrat L, Li S, Torsæter O (2013d) A coreflood investigation of nanofluid enhanced oil recovery in low-medium permeability Berea sandstone. Society of petroleum engineers. Paper SPE 164106-MS. doi:10.2118/164106-MS

Houston SJ (2007) Formation waters in petroleum reservoirs: their controls and applications. PhD thesis, University of Leeds

ISO 14887:2000(E) (2000) Sample preparation-dispersing procedures for powders in liquids. International Organization for Standardization, Geneva

Jabbar MY, Al-Hashim HS, Abdallah W (2013) Effect of brine composition on wettability alteration of carbonate rocks in the presence of polar compounds. Society of petroleum engineers. SPE-168067-MS. doi:10.2118/168067-MS

Jadhunandan PP, Morrow NR (1995) Effect of wettability on waterflood recovery for crude-oil/brine/rock systems. Society of petroleum engineers. Paper SPE 22597-PA. doi:10.2118/ 22597-PA
Kumar M, Fogden A, Morrow NR, Buckley JS (2010) Mechanisms of improved oil recovery from sandstone by low salinity flooding. Paper SCA 2010-25 presented at the 24th international symposium of core analysts, Halifax, Canada

Lager A, Webb KJ, Black CJJ, Singleton M, Sorbie KS (2006) Low salinity oil recovery-an experimental investigation. Paper SCA2006-36 presented at the society of core analyst, Trondheim, Norway

Loahardjo N, Xie X, Morrow NR (2010) Oil recovery by sequential waterflooding of mixed-wet sandstone and limestone. Energy Fuels 24(9):5073-5080

Morrow NR (1990) Wettability and its effect on oil recovery. J Pet Tech 42 (12): 1476-1484. SPE-21621-PA. doi:10.2118/21621-PA

Morrow NR, Buckley JS (2011) Improved oil recovery by lowsalinity waterflooding. JPT SPE Journal Paper, Distinguished Author Series: 106-112. doi:10.2118/129421-JPT

Morrow NR, Tang GQ, Valat M, Xie X (1998) Prospects of improved oil recovery related to wettability and brine composition. J Petrol Sci Eng 20(3-4):267-276. doi:10.1016/S0920-4105(98)00030-8

Potts DE, Kuehne DL (1988) Strategy for alkaline/polymer flood design with berea and reservoir-rock corefloods. SPERE 3(4):1143-1152. doi:10.2118/14935-pa

Rao Y (2010) Nanofluids: stability, phase diagram, rheology and applications. Particuology 8:549-555

Rivet SM (2009) Coreflooding oil displacements with low salinity brine. Master Thesis, University of Texas at Austin

Skauge A (2013) Modelling of EOR/IOR processes-upscaling from pore to reservoir scale. Society of petroleum engineers. Extended abstracts of SPE workshop in artic, Harstad

Skauge T, Spildo K, Skauge A (2010) Nano-sized particles for EOR. Soc Pet Eng. doi:10.2118/129933-MS

Tang GQ, Morrow NR (1997) Salinity, temperature, oil composition and oil recovery by waterflooding. SPE Reserv Eng 12(4):269-276. doi:10.2118/36680-pa

Tang GQ, Morrow NR (1999a) Influence of brine composition and fines migration on crude oil/brine/rock interactions and oil recovery. J Pet Sci Eng 24(2-4):99-111

Tang GQ, Morrow NR (1999) Oil recovery by waterflooding and imbibition-invading brine cation valency and salinity. Paper SCA-9911 presented at the 1999 international symposium of the society of core analysis, Golden, Colorado, USA

Treiber LE, Duane LE, Archer L, Owens WW (1971) A laboratory evaluation of the wettability of fifty oil-producing reservoirs. SPE J 12:531-540

Vledder P, Foncesca JC, Wells T, Gonzalez I, Ligthelm D (2010) Low salinity waterflooding: proof of wettability alteration on a field wide scale. Society of petroleum engineers. Paper SPE129564-MS. doi:10.2118/129564-MS

Webb KJ, Black CJJ, Al-Ajeel H (2004) Low salinity oil recoverylog-inject-log. Society of petroleum engineers. Paper SPE98379-MS. doi:10.2118/89379-MS

Wikianswers (2014) http://wiki.answers.com/

Worden RH, Coleman ML, Matray JM (1999) Basin scale evolution of formation waters: a diagenetic and formation water study of the Triassic Chaunoy Formation, Paris Basin. Geochimica et Cosmochimica Acta 63(17):2513-2528. doi:10.1016/S00167037(99)00121-0

Wu S, Firoozabadi A (2010) Effect of clay, brine and chemical treatment in the wettability alteration of berea rock. Society of petroleum engineers. SPE-129542-MS. doi:10.2118/129542-MS

Yildiz HO, Valat M, Morrow NR (1999) Effect of brine composition on wettability and oil recovery of a prudhoe bay crude oil. Pet Soc Can. doi:10.2118/99-01-02

Yu W, Xie H (2012) A review on nanofluids: preparation, stability mechanisms, and applications. J Nanomater. doi:10.1155/2012/ 435873 
Zekri AY, Nasr MS, Al-Arabai ZI (2011) Effect of LoSal on wettability and oil recovery of carbonate and sandstone formation. International petroleum technology conference. IPTC14131-MS. doi:10.2523/14131-MS

Zhang Y, Xie X, Morrow NR (2007) Waterflood performance by injection of brine with different salinity for reservoir cores. Society of petroleum engineers. Paper SPE 109849. doi:10.2118/ 109849-MS
Zhang T, Murphy M, Yu H, Bagaria H, Nielson B, Bielawski C, Johnston K, Huh C, Bryant S (2013) Investigation of nanoparticle adsorption during transport in porous media. Society of petroleum engineers. Paper SPE 166346-MS. doi:10.2118/ 166346-MS 